\title{
Pelatihan Penulisan Karya Ilmiah menggunakan Microsoft Word dan Manajer Referensi Mendeley Menggunakan Media Pembelajaran Online (Zoom dan Live Streaming Youtube)
}

RA Dinasty Purnomoasri*1, Kukuh Kurniawan DS ${ }^{1}$, Rasyiid Latiif Amhudo ${ }^{1}$, Reki Arbianto ${ }^{1}$, Suryo Handoyo $^{1}$, Erni Mulyandari ${ }^{1}$, Herman Susila ${ }^{1}$

\author{
${ }^{1}$ Fakultas Teknik, Jurusan Teknik Sipil, Universitas Tunas Pembangunan, Surakarta \\ *e-mail: dinasty@lecture.utp.ac.id
}

\begin{abstract}
Abstrak
Penulisan karya tulis ilmiah adalah keterampilan yang sangat penting untuk dimiliki sivitas akademika dalam menyampaikan gagasan secara ilmiah dan bertanggung jawab. Microsoft Word memilik banyak fitur-fitur yang dapat dimanfaatkan dalam penulisan karya ilmiah penelitian akan tetapi tidak semua sivitas akademika di UTP Surakarta dapat menggunakan fitur-fitur yng tersedia yang dikarenakan ketidaktahuan akan informasi penggunaan fitur pada Microsoft Word. Kehadiran Mendeley sebagai open source of reference and citation manager yang dapat menonjolkan kutipan kalimat atau paragraf dan mencantumkan referensi otomatis di halaman akhir tulisan mahasiswa diharapkan dapat mengarahkan mahasiswa untuk meningkatkan tulisan akademiknya. Metode pelaksanaan dilakukan dengan cara daring/ Online menggunakan media Zoom dan Youtube. Pelaksanaan pelatihan penulisan karya ilmiah ini diikuti oleh mahasiswa dan dosen UTP Surakarta, melalui daring pada Zoom dan Youtube. Kegiatan ini cukup membantu dan keberadaan e-book panduan yang sudah dibuat oleh tim diminati sehingga kedepannya diharapkan dapat dimanfaatkan dan meningkatkan mutu penulisan sivitas akademika UTP.
\end{abstract}

Kata kunci: Penulisan, Microsoft Word, Mendeley, Karya Ilmiah

\begin{abstract}
Writing scientific papers is a very important skill for academics to have in conveying ideas scientifically and responsibly. Microsoft Word has many features that can be used in writing scientific research papers, but not all academics at UTP Surakarta can use the available features due to ignorance of information on using features in Microsoft Word. Mendeley's presence as an open-source reference and citation manager who can highlight a sentence or paragraph quotes and include automatic references on the final page of student writing is expected to lead students to improve their academic writing. The implementation method is carried out onlinelonline using Zoom and Youtube media. The implementation of this scientific writing training was attended by students and lecturers of UTP Surakarta, online on Zoom and Youtube. This activity is quite helpful and the existence of a guide e-book that has been made by the team is in demand so that in the future it is hoped that it can be used and improve the quality of writing for UTP academics.
\end{abstract}

Keywords: Writing, Microsoft Word, Mendeley, Scientific Paper

\section{PENDAHULUAN}

Kegiatan sivitas akademika Universitas Tunas Pembangunan (UTP) Surakarta pastinya tidak pernah lepas dari penulisan laporan baik menulis Tugas Akhir, Skripsi, Tesis, Disertasi, Karya Ilmiah, Artikel Publikasi Ilmiah maupun dokumen akademik yang lain dengan menggunakan software komputer (Microsoft Word) memerlukan pemahaman lanjut software dan bukanlah sebuah hal yang mudah. Kendala yang sering dihadapi oleh mahasiswa maupun dosen saat mengetik dengan piranti lunak (software) adalah mengelola pengetikan naskah dengan format yang sesuai dengan aturan yang ditentukan oleh institusi (Nursalam, 2016 2013). Penulisan laporan merupakan hal penting bagi sivitas akademika di Universitas Tunas Pembangunan (UTP) Surakarta, hal ini di dukung dengan ada UU Nomor 12 Tahun 2012 Tentang Pendidikan Tinggi.

Penulisan karya tulis ilmiah adalah keterampilan yang sangat penting untuk dimiliki sivitas akademika dalam menyampaikan gagasan secara ilmiah dan bertanggung jawab (Hantono, Afri, dan Maulina 2021). Microsoft Word memilik banyak fitur-fitur yang dapat dimanfaatkan dalam penulisan karya ilmiah penelitian akan tetapi tidak semua sivitas 
akademika di UTP Surakarta dapat menggunakan fitur-fitur yng tersedia yang dikarenakan ketidaktahuan akan informasi penggunaan fitur pada Microsoft Word. Akibatnya tidak jarang laporan terlihat amburadul dengan tata letak penomoran, paragraf, tabel, gambar dan lainnya tidak nyaman untuk di baca. Hal ini tidak hanya menimbulkan masalah format yang amburadul akan tetapi juga dapat menimbulkan tingginya tingkat plagiasi. Berdasarkan permasalahan tersebut maka selain pemanfaatan Microsoft Word penting juga adanya penggunaan aplikasi Mendeley yang dapat meningkatkan kemampuan dan produktivitas mahasiswa dalam hal referensi dan sitasi yang berujung pada meningkatnya mutu Pendidikan (Anwar, Sabrina, dan Cahyani 2021).

Kehadiran Mendeley sebagai open source of reference and citation manager (Zaugg dkk. 2011) yang dapat menonjolkan kutipan kalimat atau paragraf dan mencantumkan referensi otomatis di halaman akhir tulisan mahasiswa diharapkan dapat mengarahkan mahasiswa untuk meningkatkan tulisan akademiknya. keterampilan. Memperkenalkan penggunaan Mendeley juga diharapkan dapat menghindari insiden dalam penulisan akademik yang dapat menjebak mahasiswa dalam masalah kutipan dan kutipan yang tidak tepat. Selain itu, Mendeley juga merupakan jejaring sosial bagi penulis dan peneliti untuk berbagi ide ilmiah dan melakukan penelitian secara kolaboratif. Terakhir, software Mendeley hanyalah sebuah alat yang dapat membantu mahasiswa untuk mengutip dan mengutip dengan benar, kejujuran akademik perlu mendapat perhatian lebih serius dari dosen untuk mengawasi tulisan mahasiswa dan memberikan umpan balik yang berarti (Basri dan Patak 2016). Keterampilan menulis sebuah laporan atau karya ilmiah merupakan modal penting bagi sivitas akademika dan kesulitan seringkali timbul dari ketidakmampuan sivitas akademika dalam memanfaatkan software penulisan secara maksimal dan masih minimnya pemahaman akan plagiat dan pencarian literatur berkualitas (Suryani dkk. 2021).

Pendampingan dalam hal penulisan terutama dalam hal formating dirasa sangat diperlukan agar untuk selanjutnya laporan penelitian, pengabdian, skripsi, dan lainnya oleh sivitas akademika di UTP Surakarta menjadi lebih baik dan tentu saja bebas dari plagiasi dengan menambahkan referensi dengan akurat menggunakan Microsoft Word dan Mendeley. Tujuan dari kegiatan Pengabdian Kepada Masyarakat ini adalah untuk meningkatkan pengetahuan bagi para peserta yakni mahasiswa pentingnya manfaat aplikasi Microsoft Word dan Mendeley sebagai manajemen referensi sumber-sumber pustaka dalam penelitian serta meningkatkan kemampuan para peserta yakni mahasiswa agar dapat mengoperasikan aplikasi Microsoft Word dan Mendeley dengan baik dan benar. Diharapkan dengan adanya kegiatan/workshop sivitas akadmika seperti dosen, mahasiswa, dan para pegawai dapat termotivasi melakukan penelitian, menulis hasil dari penelitian, dan mempublikasikan penelitian pada jurnal ilmiah di tingkat nasional maupun internasional (Firmansyah, Qadri, dan Arham 2020). Oleh karena itu, Prodi Teknik Sipil Universitas Tunas Pembangunan berinisiatif melakukan kegiatan pengabdian kepada masyarakarta untuk menukung kemampuan sivitas akademika dalam memanfaatkan Microsoft Word dan software referensi Mendeley.

\section{METODE}

Metode Pelaksaan dalam Pengabdian Masyarakat terdiri dari dua tahap yaitu Tahap Persiapan dan Tahap Pelaksanaan. Pada tahap persiapan yang dilaksanakan oleh tim yaitu melakukan diskusi terkait informasi cara penulisan yang diharapkan akan sesuai dan tepat digunakan oleh sivitas akademika khususnya dosen dan mahasiswa lingkup UTP Surakarta, metode penyampaian yang akan digunakan mengingat sedang ada pandemi Covid-19. Selanjutnya tim menentukan dasar kepenulisan yang akan digunakan dan disampaikan serta memilih/menunjuk pembicara yang dirasa mampu menyampaikan tentang kepenulisan. 
Pada tahap pelaksanaan dilakukan pembuatan materi dan buku panduan kepenulisan oleh tim kemudian melakukan persiapan terkait workshop melalui Zoom dan Live Streaming Youtube, promosi secara Online kepada sivitas akademika UTP Surakarta, analisis ruang dan membuat buku/panduan kepenulisan yang bisa dimanfaatkan kedepannya oleh sivitas akademika UTP Surakarta. Pendekatan yang dilakukan dengan peran aktif mitra yang mengikuti workshop penyusunan karya tulis ilmial menggunakan Microsoft Word sehingga menjadi lebih mahir dan efektif dalam bekerja atau menyusun laporan. Serta mitra juga mengikuti pelatihan menggunakan aplikasi reference manajer Mendeley.

\section{HASIL DAN PEMBAHASAN}

Kegiatan Pengabdian Masyarakat (PKM) dilaksanakan secara daring memalui Zoom dan Live Streaming Youtube dengan judul Workshop: "Penulisan Karya Ilmiah menggunakan Microsoft Word dan Manajer Referensi Mendeley" yang dilaksanakan pada tanggal 27 Januari 2022. Lefleat Online kegiatan workshop dapat dilihat pada gambar 1. Kegiatan ini diikuti oleh sivitas akademika UTP Surakarta secara gratis/free. Agar kegiatan berjalan sesuai dengan rencana maka susunan acara dapat dilihat pada Tabel 1.

Tabel 1. Susunan Acara Workshop

\begin{tabular}{cccc}
\hline No & Pukul (WIB) & Agenda Acara & Pelaksana \\
\hline $\mathbf{1}$ & $10.00-10.30$ & Registrasi & Panitia Workshop \\
\hline $\mathbf{2}$ & $10.30-10.45$ & Pembukaan Workshop & MC \\
& & Doa & Reki Arbianto, S.T., M.Eng \\
\hline $\mathbf{3}$ & $10.45-11.45$ & $\begin{array}{c}\text { Presentasi Pembicara dan Tanya } \\
\text { Jawab Penggunaan Aplikasi } \\
\end{array}$ & Manajemen Referensi Mendeley \\
& & Kukuh Kurniawan DS, S.T., M.Eng & Pembicara 2 \\
\hline $\mathbf{4}$ & $12.00-13.00$ & Presentasi Pembicara dan Tanya & \\
& & Jawab Penulisan karya ilmiah \\
& & menggunakan Microsoft Word & Pembicara 1 \\
& & RA Dinasty Purnomoasri, S.T., M.T. & \\
\hline $\mathbf{5}$ & $13.00-13.05$ & Penutup & MC \\
\hline
\end{tabular}

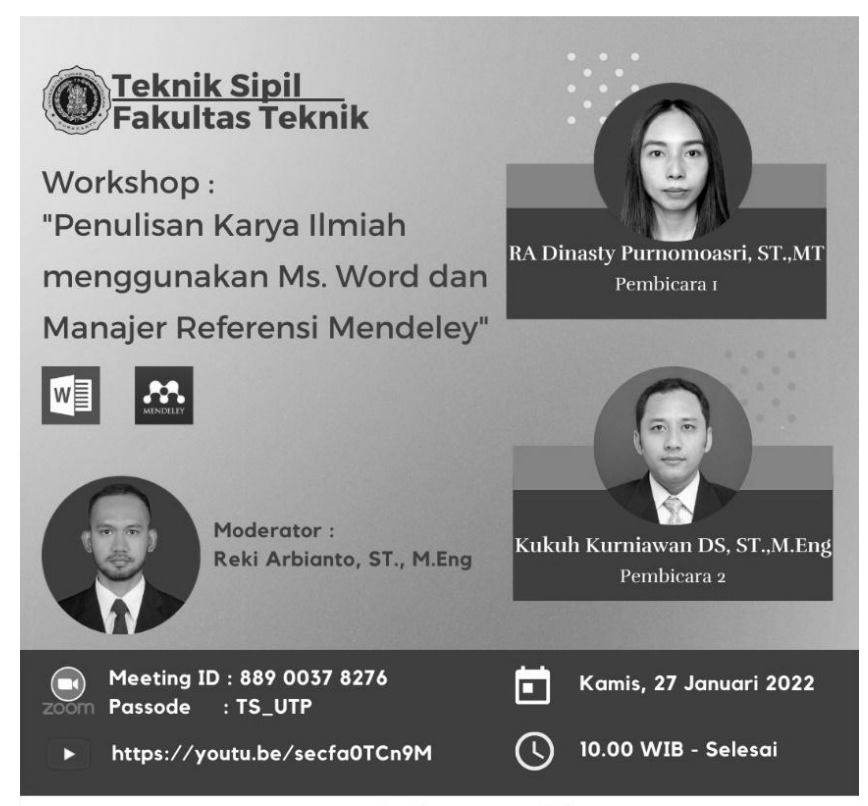

www.tsipil.utp.ac.id

Gambar 1. Lefleat kegiatan workshop 
Kegiatan workshop dilaksanakan memalui Zoom Meeting dan juga Live Streaming Youtube. Diikuti oleh dosen dan mahasiswa khususnya sivitas akademika UTP Surakarta dapat dilihat pada gambar 2. Materi pelatihan pada webinar sebagai berikut:

\section{Pemateri Aplikasi Manajer Referensi Mendeley}

Mendeley merupakan software yang mempunyai fungsi untuk mengintregrasikan "citation \& reference manager". Perangkat lunak ini membantu dalam mengelola referensi, mengambil metadata dokumen referensi, mengelompokkan, membuat catatan, menyusun daftar Pustaka dll. Beberapa fitur andalan Mendeley antara lain :

- Dapat berjalan pada MS Windows, Mac, ataupun Linux.

- Menampilkan metadata dari sebuah file PDF secara otomatis.

- Backup dan sinkronisasi data dari beberapa komputer dengan akun Online.

- Smart filtering dan tagging.

- PDF viewer dengan kemampuan anotasi dan highlighting.

- Impor dokumen dan makalah penelitian dari situs- situs eksternal (misalnya PubMed,

- Google Scholar, arXiv, dll).

- Integrasi dengan berbagai perangkat lunak pengolah kata seperti MS Word, OpenOffice,

- dan LibreOffice.

- Fitur jejaring sosial.

- Android, iPhone dan iPad app.

- Free web storage sebesar 2 GB yang dapat dimanfaatkan sebagai Online backup

\section{Pemateri Penulisan Karya Ilmiah menggunakan Microsoft}

Microsoft Word adalah aplikasi pembuat dokumen yang lazim digunakan pada sivitas akademik dalam membuat pelaporan atau karya ilmiah. Penyampaian materi diawali dengan penjelasan mengenai standar penulisan karya ilmiah, sistematika penulisan yang dimulai dari judul, abstrak, pendahuluan, tinjauan pustaka metodologi, hasil dan pembahasan, kesimpulan dan saran, daftar pustaka serta lampiran (Firmansyah, Qadri, dan Arham 2020). Selanjutnya pemateri mendemonstrasikan dan menjelaskan fitur-fitur awal yang digunakan sebelum membuat laporan seperti melakukan setting pada ukuran kertas, melakukan mofikasi pada style normal agar penulisan huruf menjadi Times new roman dengan ukuran 12 pt dengan jarak antar paragraph 6 pt serta melakukan setting margin agar menjadi sesuai dengan standar penulisan laporan.

Pemateri kemudian melanjutkan dengan memberikan pemaparan praktik yang didasarkan pada struktur penulisan laporan. Dimulai dari penggunaan Heading untuk setiap judul bab dan subab. Hal ini penting karena konsistensi merupakan hal utama yang harus ada di dalam penulisan sebuah karya ilmiah profesional (Prasetyo 2019) untuk itu Microsoft Word menyediakan fasilitas style. Setelah Heading dilakukan pada sub bab dijelaskan cara pemberian penomoran dengan memanfaatkan fitur Numbering dan Multilevel List yang selain pada sub bab juga dimanfaatkan pada sub sub bab.

Untuk mempermudah pencarian dan navigasi dalam karya ilmiah maka diperlukan penomoran halaman. Penomoran romawi kecil digunakan dibagian awal dan penomoran latin digunakan pada bagian isi hingga akhir. Maka pemateri memberikan informasi dan praktek langsung membuat halaman dengan fitur insert $>$ footer $>$ edit Footer yang selanjutnya gunakan fitur page number dan untuk memisahkan digunakan menu page break (Faizal 2016). Hal ini didukung pula dengan keberadaan navigation pane yang memudahkan penulis untuk melakukan penjelajahan dokumen tanpa perlu melakukan scroll bar berkali-kali (Prasetyo 2019). 
Gambar merupakan salah satu unsur utama dalam suatu karya ilmiah, hal ini di dikaitkan dengan kemampuan penulis dalam menampilkan ilustrasi yang baik. Dalam gambar selain gambar itu sendiri yang juga perlu menjadi perhatian adalah keberadaan keterangan gambar yang dalam Microsoft Word penulis dapat memanfaatkan fitur caption. Selain untuk keterangan gambar, caption juga dimanfaatkan dalam pemberian keterangan pada tabel agar keterangan dapat menjadi konsisten. Pemateri juga menjelaskan bagaimana cara untuk mengatur ukuran gambar agar ukuran file tidak terlalu besar dan sesuai kebutuhan dengan pemanfaatan fitur compression options.

Terakhir pemateri menyampaikan bagaimana cara membuat Daftar isi, Gambar dan Tabel secara otomatis karena tentunya jika dikerjakan secara manual tentnu akan merepotkan. Karena fitur style dan caption yang telah dimanfaatkan maka dapat dibuat daftar isi secara otomatis. Fitur yang dimanfaatkan berada pada menu references yang untuk daftar isi dipilih menu table of contents dan untuk gambar serta tabel dipilih menu insert table of figure. Daftar isi, daftar gambar dan tabel dapat dilakukan update jika terjadi perubahan halaman.

Materi di atas disampaikan dalam bentuk demonstrasi praktik secara langsung agar para peserta workshop bisa langsung mengikuti. Pemanfaatan fitur-fitur di atas dirasa perlu sehingga penulis bisa membuat laporan dalam satu file yang lengkap dan utuh. Selanjutnya setelah penyampaian materi adalah sesi tanya jawab.

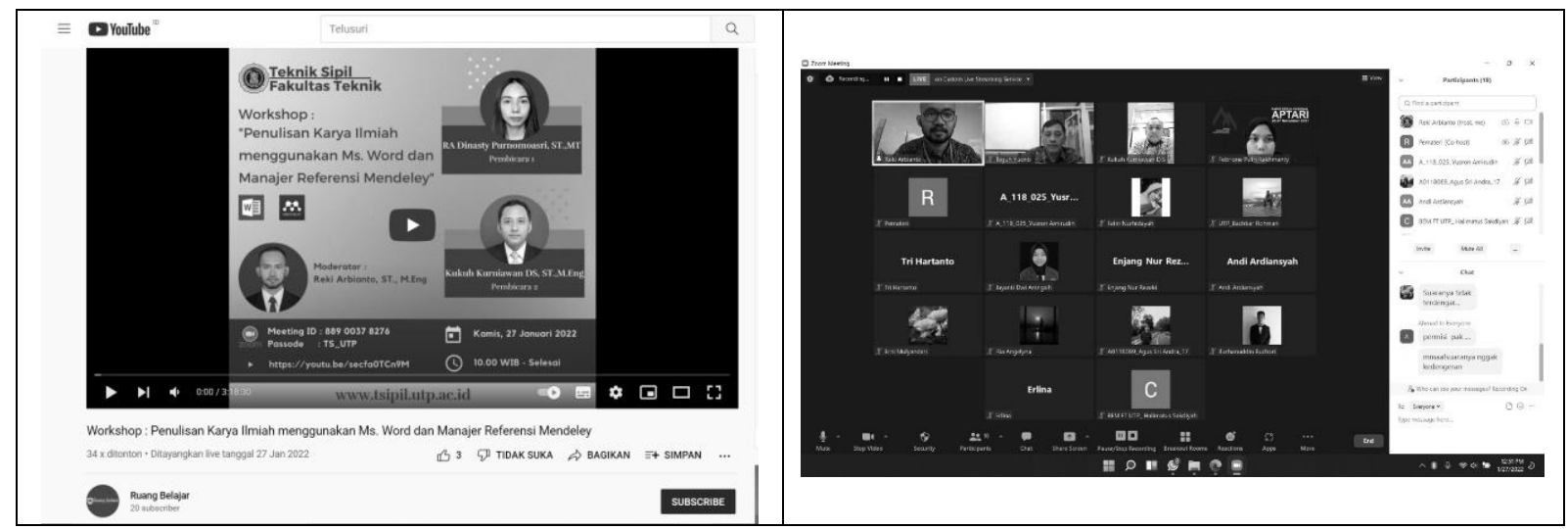

Gambar 2. Live Streaming Youtube dan Zoom Meeting

Selain melaksanakan workshop pemateri juga membuat buku panduan dalam bentuk e-book yang diharapkan juga dapat dimanfaatkan oleh sivitas akademika UTP Surakarta. Dalam buku panduan tersebut terdapat materi yang disampaikan pada saat workshop. Gambar 3 menunjukkan gambar cover e-book panduan yang dapat di unduh di link https://youtu.be/secfa0TCn9M. 


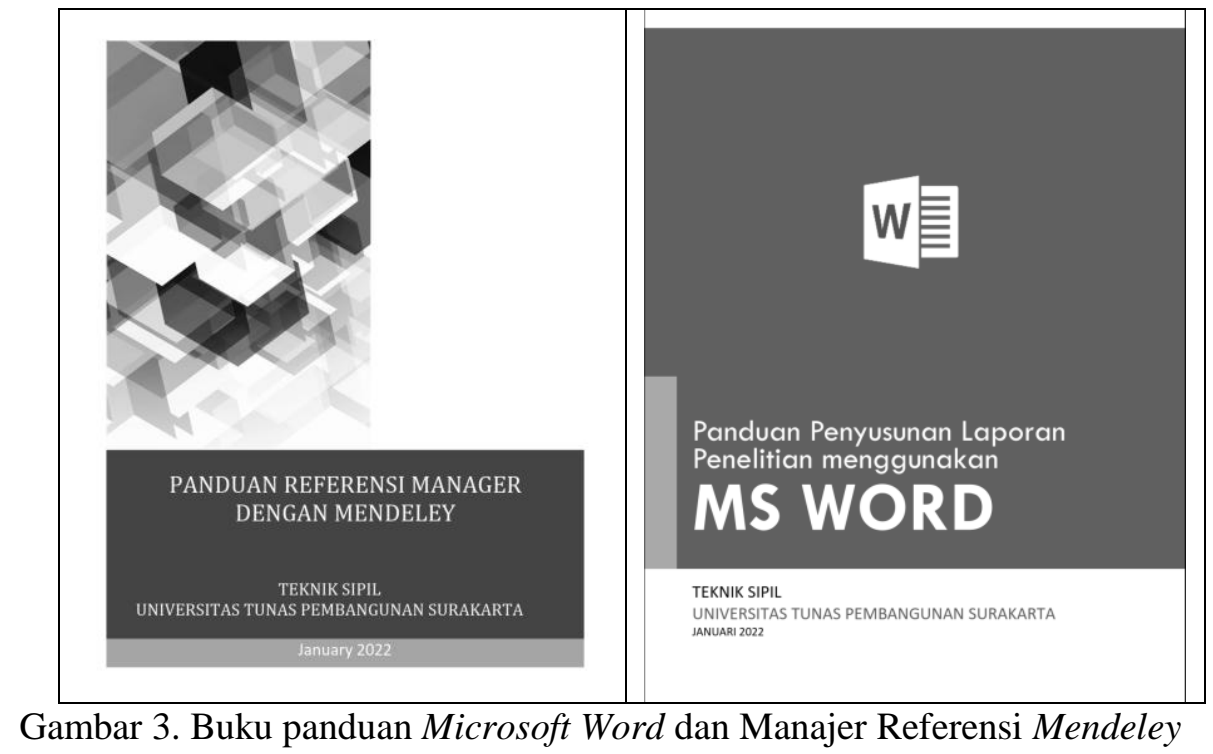

\section{KESIMPULAN}

Hasil kegiatan PKM dengan media Zoom dan Live Streaming Youtube menunjukkan bahwa kegiatan workshop: "Penulisan Karya Ilmiah menggunakan Microsoft Word dan Manajer Referensi Mendeley" untuk sivitas akademika UTP Surakarta sangat diperlukan karena masih banyaknya dosen dan mahasiswa yang belum memanfaatkan fitur-fitur di Microsoft Word untuk kemudahan penulisan serta penggunaan Manajer Referensi Mendeley dalam melakukan sitasi. Hal ini terbukti dengan antusiasme sivitas akademika dalam bertanya terkait materi serta permintaan materi oleh para dosen untuk membantu mahasiswa dalam melakukan penulisan karya ilmiah. Tim juga menyusun buku panduan dalam bentuk $e$-book yang diharapkan dapat dimanfaatkan oleh sivitas akademika UTP dalam meningkatkan mutu penulisan laporan.

\section{UCAPAN TERIMA KASIH}

Pengabdian masyarakat ini dapat dilaksanakan dengan baik berkat dukungan dari berbagai pihak, untuk itu penulis ucapkan terima kasih kepada Universitas Tunas Pembangunan Surakarta yang telah mendanai program pengabdian masyarakat dan kepada sivitas akademik UTP Surakarta yang sudah berpartisipasi dalam kegiatan pengabdian masyarakat ini.

\section{DAFTAR PUSTAKA}

Anwar, Rosyida Nurul, Syauzan Sabrina, dan Arin Nur Cahyani. 2021. "Pelatihan Penggunaan Software Mendeley Untuk Meningkatkan Keterampilan Menulis Karya Ilmiah Mahasiswa." AN-NAS: Jurnal Pengabdian Masyarakat 1(1): 1-6.

Basri, Muhammad, dan Andi Anto Patak. 2016. "Exploring Indonesian students' perception on Mendeley Reference Management Software in academic writing." ICITACEE 2015 2nd International Conference on Information Technology, Computer, and Electrical Engineering: Green Technology Strengthening in Information Technology, Electrical and Computer Engineering Implementation, Proceedings: 8-13.

Faizal, Mochammad. 2016. "Trik Praktis Ms Word untuk Menyusun Laporan Penelitian."

Firmansyah, Amrie, Resi Ariyasa Qadri, dan Amardianto Arham. 2020. "Pelatihan melalui web seminar tentang kiat dan motivasi penulisan artikel hasil penelitian pada jurnal ilmiah." INTERVENSI KOMUNITAS Jurnal Pengabdian Masyarakat 2(1): 21-27.

Hantono, Hantono, Evan Afri, dan Intan Maulina. 2021. “Asistensi Penulisan Karya Tulis 
Ilmiah Terakreditasi Sinta." Dedikasi Sains dan Teknologi 1(2): 106-11.

Nursalam, 2016, metode penelitian. 2013. 53 Journal of Chemical Information and Modeling Cara Mudah Penulisan Karya Ilmiah dengan MS. Word 2010.

Prasetyo, Kristian Agung \& Febrian. 2019. Panduan Karya Tulis Ilmia dengan Microsoft Word 365 dan 2019. Indonesia: PT Elex Media Komputindo.

Suryani, Ani Wilujeng dkk. 2021. "Penguatan Pemanfaatan Software Penulisan Untuk Meningkatkan Soft Skills Mahasiswa.” Sinergi: Jurnal Pengabdian 3(1): 1-7.

Zaugg, Holt, Richard E. West, Isaku Tateishi, dan Daniel L. Randall. 2011. "Mendeley: Creating communities of scholarly inquiry through research collaboration." TechTrends 55(1): 32-36. 